\title{
FUNK: ENGAJAMENTO JUVENIL OU OBJETIVAÇÃO FEMININA?
}

\author{
JACIRA GIL BeRNARDES \\ Universidade Federal do Rio Grande do Sul (UFRGS), Porto Alegre, \\ Rio Grande do Sul, Brasil \\ Paula Pinhal de Carlos \\ Centro Universitário La Salle (Unilasalle), Canoas, Rio Grande do \\ Sul, Brasil \\ Aline AcCORSSI \\ Centro Universitário La Salle (Unilasalle), Canoas, Rio Grande do \\ Sul, Brasil
}

\begin{abstract}
RESUMO: O artigo tem como objetivo analisar os sentidos atribuídos ao gênero no funk (dança) que permeiam as aulas e apresentações dessa dança em uma comunidade de periferia em Canoas, RS. Para isso foi realizada uma pesquisa qualitativa de cunho exploratório. Realizamos oito horas de observação de uma prática (aulas e apresentações) de Funk. Os resultados mostram que, por um lado, o ensino da dança pode se configurar como um importante instrumento de transformação dos jovens, visto que há grande satisfação por parte deles em participar das oficinas de funk, mas, por outro, pode representar mais um espaço de dominação e naturalização de lugares sociais que reforçam as diferenças de gênero.
\end{abstract}

Palavras-chave: Funk. Dança. Gênero. Juventude. 
INTRODUÇÃO

O funk como música e dança sempre nos inquietou. Cada vez que ouvimos ou falamos a palavra funk, ela vem acompanhada de um infindável número de expressões pejorativas e de desagrado, vindo de pessoas de variadas idades, nível socioeconômico ou escolaridade. Isso ainda nos surpreende. Nas redes sociais, há milhares de "frases clássicas" que demonstram o ódio de muitos por esse gênero. As relações entre funk e violência e, principalmente, entre funk e sexualidade permeiam esses diálogos, sendo o ritmo considerado como atentado ao pudor, pornografia e péssima influência à juventude.

A possibilidade de refletir sobre o tema nos leva a uma série de questionamentos. Será que essa visão, que pode ser considerada preconceituosa, reflete uma realidade? Será que inúmeras pessoas deixam de conhecer o funk por medo? Mesmo que não possamos responder a essa questão nesse momento, não é difícil perceber que o funk está associado à violência, às drogas, à criminalidade, às gangues, bem como à sexualidade e à utilização do corpo. Será que as pessoas em geral conhecem o funk o suficiente para não estigmatizá-lo? E quem pratica essa dança também pensa assim? Quais as diferenças que aparecem entre dançarinos de funk relacionados ao gênero?

Neste artigo buscamos responder a seguinte questão: quais são os sentidos atribuídos ao gênero no funk (dança) que permeiam uma Oficina de Funk para a juventude, numa comunidade de periferia no bairro de Canoas, Rio Grande do Sul? Por meio da observação das práticas corporais vivenciadas em oficinas de funk e apresentações externas de um grupo de jovens, pretendemos problematizar e analisar o que foi registrado dessas observações, procurando refletir sobre como o funk, na dança, se comunica na perspectiva de gênero.

Para tanto, apresentaremos alguns dados do funk no Brasil, bem como sobre a juventude e a importância do ritmo para a vida de jovens de uma comunidade de periferia no bairro Guajuviras, localizado em Canoas. Amparamo-nos nas obras de Dayrel (2001) para os temas da juventude e do funk e em Weller (2005) para a temática de gênero e juventude.

FUNK E JUVENTUDE

O funk é tido para nós como um gênero musical que surgiu na década de 1930, nos Estados Unidos, com artistas como James Brown e Melvin Parker. 
Naquele momento, o funk ainda não tinha a sua principal característica: o swing.

O funk carioca é inspirado no Miami Bass, um ritmo da Flórida, com músicas mais erotizadas e batidas mais rápidas. Para os especialistas, o funk carioca não pode ser chamado dessa forma: é apenas uma variação do Miami Bass (LIMA, 2008, p. 1).

Ao final da década de 1980, começaram a ser lançadas no Brasil músicas com letras em português retratando o cotidiano dos frequentadores dos bailes funk, com temas como violência e pobreza. "Na época, o funk falava sobre as drogas, as armas, os comandos, mas artistas desta fase, como Claudinho e Buchecha, evoluíram para outros tipos de tema" (MEIRELLES apud ARAÚJO, 2005, p. 1). Os temas passaram a ser sociais e hoje estão mais voltados para a sensualidade, sexualidade e sexo.

Os bailes funk, por outro lado, começaram a ficar violentos, com brigas entre gangues ${ }^{1}$, havendo a necessidade de intervenção da polícia:

A pressão da polícia, da imprensa e a criação de uma CPI na Assembléia do Rio de Janeiro em 1999 e 2000 acabaram com a violência em grande parte dos bailes, ao mesmo tempo que as músicas se tornaram mais dançantes e as letras, mais sensuais. Esta nova fase do ritmo, descrita por alguns como o new funk, se tornou sucesso em todo o país e conquistou lugares antes dominados por outros ritmos, como o Carnaval baiano (ARAÚJO, 2005, p. 1).

Contudo, o funk também se tornou uma atração comercial com exploração da mídia da música, da dança, do corpo da mulher e da erotização de crianças. Diante de tal quadro, feministas lideram críticas ao funk e à utilização de termos como "cachorras", "popozudas", "piranhas"e "safadinha"2 dentre outros que objetificam as mulheres. Podemos lembrar que outros ritmos brasileiros incluem o erotismo tanto na letra da música como na dança. Esse erotismo está presente, por exemplo, tanto no axé quanto no próprio samba."Enfim, o erotismo das danças, a subdivisão dos dançarinos por gênero, o caráter performático do evento e a interdependência entre dança e música aparecem no funk, mas têm precedentes na memória de danças e músicas afro-descendentes no Brasil." (LIMA, 2008, p. 1).

A relação da sociedade com os funkeiros é igual ao tratamento dispensado aos moradores das favelas, pobres e negros: são tratados como se fossem marginais. No entanto, nos dias de hoje, o funk se expandiu, ocupando um espaço na classe média do Rio de Janeiro e inclusive de outras cidades do país. 
A desterritorialização e reterritorialização promovidas pelo funk, a briga de fronteira entre classes e grupos sociais prosseguem. [...] Com o funk, a favela tem-se inserido nos espaços de concepção-produção-difusão e recepção musical, nos espaços de fruição social e de debate cultural. As divisórias e barreiras se movem, desarrumando e rearrumando territórios, provocando uma multiterritorialidade. O funk burla sentinelas e atravessa as trincheiras da cidade (ARRUDA et al., 2010, p. 422-423).

Ao discutirmos a questão do funk é necessário pensar a questão da juventude. $O$ trabalho com jovens requer um conhecimento especial, uma vez que eles vivenciam a realidade de forma diferenciada. A juventude hoje é influenciada pela rapidez do mundo pós-moderno, a comunicação é on-line, as relações iniciam com o"pegar ou o "ficar", que é passageiro, as relações de consumo são muito relevantes e as interações entre as pessoas são instantâneas, sejam elas pessoais, pelo celular, pelo computador ou pela televisão. Os jovens estão constantemente fazendo escolhas que lhes são próprias e que mudam a cada dia. A linguagem é diferenciada, agrupam-se e se reagrupam constantemente. Sposito (2006, p. 100) nos diz que "é preciso considerar que o momento da juventude é rico em manifestação da sociabilidade".

Segundo Dayrell (2003, p. 42), "a juventude constitui um momento determinado, mas não se reduz a uma passagem; ela assume uma importância em si mesma." Os jovens pobres, como outros grupos no Brasil, têm dificuldade de acessar a cultura e o lazer, o que os leva muitas vezes à formação de grupos para a sua sociabilidade. Esses mesmos jovens, segundo Catani e Gilioli (2008), não têm espaços públicos que os acolham e recorrem às gangues e tribos urbanas para utilizá-las como espaço de socialização.

Em seu tempo livre, "os jovens constroem suas próprias normas, expressões culturais, ritos, simbologia e modos de ser que os diferenciam do denominado mundo adulto" (BRENNER et al., 2005, p. 176). E muitos jovens utilizam o seu tempo livre dedicando-se à música.

A música é o principal produto cultural consumido pelos jovens não só em Belo Horizonte ou no Brasil, mas também em outros países. [...] A música acompanha os jovens em grande parte das situações no decorrer da vida cotidiana: música como fundo, música como linguagem comunicativa que dialoga com outros tipos de linguagem, música como estilo expressivo e artístico; são múltiplas as dimensões e os significados que convivem no âmbito da vida interior e das relações sociais dos jovens, sendo mais vivida do que apenas escutada (DAYRELL, 2001, p. 21). 
MÉTOdo

$\mathrm{Na}$ busca por respostas realizamos uma pesquisa com abordagem qualitativa (MINAYO, 2007), de cunho exploratório (SILVEIRA; CÓRDOVA, 2009), utilizando-se como técnica a observação (BELEl et al., 2006). Os sujeitos da pesquisa foram jovens participantes de uma oficina de funk realizada na Casa das Juventudes do Bairro Guajuviras, localizado em Canoas, no Rio Grande do Sul.

O estudo foi realizado pela observação de aulas da oficina de funk e de apresentações do mesmo grupo. As apresentações ocorreram em locais públicos. O total de horas observado foi oito, divididos em três encontros que ocorreram ao longo de um mês e duas apresentações. Os participantes das aulas giravam em torno de 30 jovens. Nas apresentações, o grupo era menor, contendo no máximo 15 integrantes. O número de jovens do sexo feminino é maior do que do sexo masculino.

De posse desses dados, procuramos problematizar e analisar o espaço de aula e apresentações, identificando práticas que evidenciam algumas representações, particularmente em relação às questões de gênero. A análise foi realizada em torno de nove eixos temáticos, sendo cada um descrito em um dos parágrafos abaixo.

\section{APRESENTAÇÃO DOS RESULTADOS}

Em relação ao espaço pedagógico, tem-se que a sala utilizada para a oficina de funk é chamada de sala de dança. Ela é considerada um espaço pedagógico por ser um espaço de aprendizagem não oficial e é pequeno para o número de participantes. Para as duas apresentações foram utilizados espaços públicos, tendo os jovens se apresentado num palco.

Quanto à ocupação do espaço, verificou-se que a sala da oficina é totalmente ocupada. Nas diversas coreografias, há a plena utilização do espaço. O palco das apresentações foi pequeno para a coreografia.

Cabe destacar também a questão das vestimentas. As jovens vestem-se com roupas comuns, como shorts jeans e camisetas, e os jovens utilizam calças jeans, alguns com modelo "cargo" e camiseta. Nos pés há alguma variação: alguns usam tênis e alguns ficam descalços. Percebemos no grupo uma tentativa de se sentir semelhante com relação às vestimentas. Em uma das oficinas, o educador comentou sobre a necessidade de arrumar um patroci- 
nador para a aquisição de camisetas personalizadas para as apresentações, para manter a uniformidade.

No que tange às categorias movimento, corpo e coreografia, contatou-se que a coreografia é rica em detalhes, com grau de dificuldade bastante grande e é baseada na valorização do corpo, ela é fechada e harmônica, baseada na música ouvida. O corpo é usado para expressar, tornando-se o espaço de comunicação daquele grupo. Os movimentos, em geral, são iguais para todos.

Outro ponto que chamou a atenção foi o discurso do educador social. O educador ou oficineiro conversa com os jovens na tentativa de valorizar o funk como forma de expressão, valorizando a música, a dança e a postura de cada integrante. Ao conversar com o grupo, impõe uma disciplina de maneira saudável, educada e é bastante respeitado pelo seu conhecimento na área da dança e pela sua técnica. Reforça constantemente a questão da não violência e a postura dos dançarinos para que transmitam uma cultura de paz. Esse educador é considerado como ídolo entre os jovens.

Outra questão examinada foi a do prazer e da alegria relacionados à atividade de lazer. Os integrantes das aulas e das apresentações demonstram muita alegria na sua dança, bem como prazer e satisfação. No horário marcado, querem logo começar a aula e, no intervalo, sentem-se insatisfeitos por terem que parar o ensaio.

Embora a oficina seja de dança e, portanto, conte com música para a sua execução, um dos temas analisados é o dos silêncios verificados. Muitos jovens ficam apenas assistindo às oficinas, sem participar, sem querer ser um integrante daquela aula. Isso ocorre tanto com meninos quanto com meninas. Esse silêncio pode ser caracterizado ou pelo nível dos jovens que ali dançam já ser mais avançado, ou por não se sentirem à vontade por não estarem inscritos formalmente na oficina. Eles silenciosamente ficam observando, às vezes acompanhando o ritmo da música com os pés.

Uma das categorias que certamente não poderia ficar de fora de um trabalho como este é a da música. Percebem-se dois tipos de música usados para a oficina: funks conhecidos e algumas músicas que são adaptadas ao ritmo funk, como músicas estrangeiras. No funk carioca "a mulher aparece como objeto do desejo sexual do homem" (MOISES, 2011). Revela-se, em muitos textos, a dominação masculina por meio da submissão. Uma das músicas usadas na oficina é Louquinha, cantada pelo McK9. Retrata a sexualidade do funk com relação à mulher. Disponibilizamos abaixo um trecho da letra da música: 


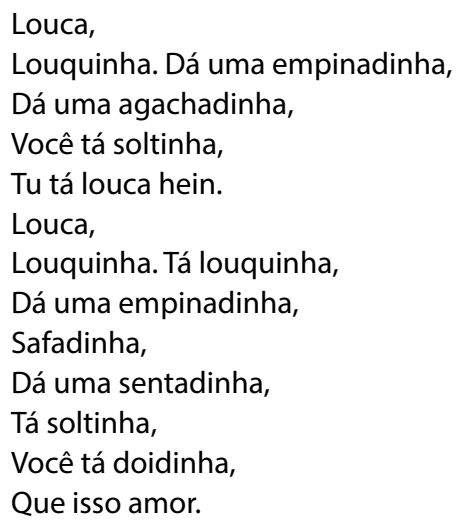

Em relação ao relacionamento do grupo, entendeu-se que este é muito bom, existindo uma competição saudável, que inclui a solidariedade. Na última oficina do ano foi solicitado ao educador, pelo próprio grupo, que organizasse um duelo, prática comum nas oficinas. O educador prontamente solicitou voluntários para o duelo e apareceram duas duplas: um casal que duelou com duas jovens. As duplas dançaram frente a frente, numa disputa coreográfica, não havendo vencedor.

\section{GÊNERO E PRESENÇA DAS MULHERES}

Uma questão que merece destaque é a presença das mulheres nas oficinas. Para tal análise utiliza-se aqui o conceito de gênero. Para Scott (1995, p. 86), gênero é"um elemento constitutivo de relações sociais fundadas sobre as diferenças percebidas entre os sexos, e o gênero é um primeiro modo de dar significado às relações de poder". A autora ainda ressalta que gênero é usualmente utilizado como sinônimo de mulheres e que houve em muitos estudos a substituição de mulher por gênero.

Por que haveria diferenciação entre homens e mulheres na sensualidade/sexualidade na dança funk? As mulheres e homens, de forma igualitária, expõem seu corpo com gestos e atitudes provocativas. Porém, atualmente, só se ouvem críticas à imagem e à dança das mulheres. As polêmicas do movimento feminista chamam a atenção da sociedade para o funk, mas pelo aspecto de objetificação das mulheres, na dança, pela utilização do corpo.

O corpo pode ser a nossa forma de comunicação e segundo Melucci $(2004$, p. 93) "o corpo é o canal de nossa afetividade." O autor ainda coloca que: 
O corpo é, enfim, para cada um de nós, o espaço pessoal, o campo daquela consciência que nos diferencia dos outros. O retorno ao corpo alimenta nossa busca de identidade. Nosso corpo é o local secreto ao qual somente nós podemos aceder e ao qual podemos voltar para sentir que existimos como indivíduos. O corpo é nossa propriedade, única e alienável, que permite nos reconhecermos numa época em que vacilam outras formas de identificação. Ninguém pode dizer o que sentimos em nosso corpo; cada um de nós é o único que pode falar de si mesmo, usando o próprio corpo. (MELUCCl, 2004, p. 93).

Assim como em outras danças, no funk percebemos uma diferenciação de desigualdades de gênero. Nas oficinas observadas percebemos uma supervalorização do jovem pelo próprio grupo. As jovens, tanto nas oficinas, como nas apresentações, estão localizadas nas filas ao final, atrás dos meninos, enfatizando o que Weller (2005) chama da "invisibilidade feminina nas culturas juvenis". Da mesma forma, Oliveira (2008) também retrata em seu texto essa inferioridade da mulher, no funk, com relação à sua identidade.

[...] constatou-se que basicamente é o homem quem tem voz e ação nesses textos, enquanto a mulher, embora seja constantemente mencionada, é geralmente o agente passivo em relação ao homem. Essa mulher assume o papel de gatinha, de cachorra, de fiel ou de amante, segundo a vontade masculina construída nos textos. Sendo assim, observaram-se antigas representações de gênero presentes nas letras de músicas funk, e construídas em novas e diversificadas roupagens que acabam retomando e enfatizando os papéis que sempre foram determinados historicamente para homens e mulheres, onde a mulher é inferior, submissa, associada ao erotismo e não tem posição ou voz de comando (OLIVEIRA, 2008, p.11-12).

A dominação masculina é reproduzida nas músicas funk, mantendo o homem sempre como o ser superior. Conforme Bourdieu (2003), se a ideia de superioridade é responsável pela dominação masculina, a incorporação dessa dominação decorre justamente do processo biologizante, fundado nos corpos. A visão androcêntrica é continuamente legitimada pelas próprias práticas que ela determina, pois suas disposições resultam da incorporação do preconceito desfavorável contra o feminino, que é instituído socialmente. Às mulheres só resta, portanto, confirmar seguidamente esse preconceito.

É ele quem organiza e comanda os encontros sexuais anunciados nos versos funk. A relação entre eles é de hierarquia masculina e a mulher é descrita 
como quem gosta dessa representação, ela está à disposição e assume conscientemente esse papel nas representações observadas (OLIVEIRA, 2008, p.11-12).

Weller (2005) ressalta que existem poucas pesquisas sobre a presença feminina nas culturas juvenis. As pesquisas na área de culturas juvenis sempre dão o enfoque ao universo masculino. Já as pesquisas dos estudos feministas deveriam ter mais "simpatia" para com as culturas juvenis.

O destaque dado aos meninos é surpreendentemente valorizado pela "plateia", que a cada entrada de um integrante "gritam", pulam, assobiam, mostrando interesse em assistir a mais uma performance dos jovens:

Este mundo é marcado pela presença de rapazes cuja afirmação de identidade masculina é forjada através de um "ethos de virilidade". Deste modo, a violência no funk é uma atribuição exterior estigmatizante, mas é também um aspecto interno aos bailes, ritualístico, que aciona a produção de territórios e identidades através da constituição das galeras. (LIMA, 2008, p. 1).

A partir desse diálogo, algumas perguntas nos ocorrem: quem autoriza essa apropriação do espaço? Será que isso acontece porque elas são meninas no funk? A regra não está explícita em lugar algum.

Quando interrogado sobre essa maior exposição dos jovens, o oficineiro declarou que cada grupo tem a sua característica e faz as suas escolhas. Afirmou que esse grupo, do ano de 2012, tem essa característica, pois os jovens dançam há mais tempo que as jovens. No ano anterior, o grupo mais experiente era das jovens, caracterizando-se pela presença das meninas na frente dos rapazes nas apresentações e oficinas.

Será que os meninos não estariam na frente também porque eles têm maior autorização para manifestar sua sexualidade do que as meninas? $\mathrm{Na}$ música funk essa autorização já é facilmente identificável quando a situação da mulher é de subordinação. O funk, segundo Lima $(2008$, p. 1)

Possui personagens como os DJ's, que produzem e comandam bailes, ou personagens como "o tigrão", "as cachorras", "as preparadas", "as popozudas", sexualizados e definidores de uma ordem de relações de gêneros em que o masculino parece ser sensual e virulento, o feminino parece ser sedutor e subordinado.

Oliveira (2008), em sua pesquisa "A identidade feminina no gênero textual música funk" em que analisa letras de músicas funk, ainda reforça a questão da inferioridade da mulher nas letras das músicas: 
[...] e vai trazer como slogan permanente a mulher em uma sitação [sic] de deboche, de promiscuidade ou de inferioridade em relação ao homem. Ainda constatamos marcas nas estruturas das letras que mostram a representação das músicas como encontros amorosos onde o papel atribuído à mulher é sempre de pertencimento ao homem ou de produto de venda e de contemplação (OLIVEIRA, 2008, p. 3).

O autor também identifica a classificação das mulheres em quatro tipos de rotulações: a fiel, a feia, a gostosa/gatinha e a mulher emancipada, sempre relacionando a mulher com a sexualidade (OLIVEIRA, 2008). De alguma forma, as jovens se sentem pouco à vontade para estarem à frente daquele grupo. Estão submetidas a um pré-estabelecimento de que as mulheres devem estar atrás dos homens e que é aceito por todas, até mesmo por quem assiste às apresentações. Ao aceitar ficar atrás e mesmo assim demonstrarem uma grande satisfação, pensam estar no seu papel, igual ao que é estabelecido de forma errônea na sociedade.

\section{CONSIDERAÇÕES FINAIS}

Quando iniciamos essa pesquisa, imaginávamos que temáticas relacionadas ao tema juventude e gênero fossem comuns nos periódicos e publicações nacionais. E também que, devido à importância da temática juventude, e por existirem muitas pesquisas na área nos últimos anos, não seria difícil localizar documentos sobre mulheres jovens. No entanto, não foi o que ocorreu, uma vez que poucos documentos sobre juventude e gênero foram localizados.

A partir da pesquisa de campo, observou-se que os jovens demonstram prazer, satisfação e realização em participar das oficinas de funk. Considerando nossas observações com relação a essas oficinas, compreendemos que, ao mesmo tempo em que visam o ensino da dança, também podem se configurar como um dos importantes instrumentos de transformação dos jovens. Ao pensarmos na relação entre oficineiro e alunos, envolvendo educação popular, se apostarmos no diálogo, pensaremos que todos os jovens são tratados da mesma forma pelo educador, que a coreografia é igual para todos, que as vestimentas são semelhantes e que a disposição na sala é decidida de forma democrática.

No entanto, foi possível notar que essa igualdade não é real, uma vez que não contempla as desigualdades de gênero. Não há o questionamento do porquê de as meninas estarem atrás e, porque não dizer, à margem dos 
rapazes. Tal fato é naturalizado por todos, inclusive pelo oficineiro, que credita tal diferença a uma peculiaridade da turma, não trazendo a temática da objetificação das mulheres nas letras de funk para a problematização dos jovens.

\section{FUNK:YOUTH ENGAGEMENT OR FEMALE OBJECTIFICATION?}

ABSTRACT: This paper aims to analyze the meanings attributed to gender in funk that permeate the dance classes and presentations in a disadvantaged community in Canoas, in the state of Rio Grande do Sul. For this end, a qualitative and exploratory research was carried out. Researchers observed Funk classes and presentations for eight hours. The results show that, on the one hand, the dance classes could be an important tool for the transformation of youth, since it offers them great satisfaction, but, on the other hand, it may represent a space of domination and normalization of social roles that reinforce the gender differences.

KEYwords: Funk. Dance. Gender. Youth.

\section{FUNK: ¿COMPROMISO JUVENIL O OBJETIVACIÓN FEMENINA?}

RESUMEN: El artículo tiene como objetivo analizar los sentidos atribuidos al género funk (danza) que permean las clases y las presentaciones de esa danza en una comunidad de la periferia en Canoas, RS. Para eso ha sido realizada una investigación cualitativa de cuño exploratorio. Realizamos ocho horas de observación de una práctica (clases y presentaciones) de Funk. Los resultados muestran que, por un lado, la enseñanza de la danza puede configurarse como un importante instrumento de transformación de los jóvenes, visto que hay gran satisfacción por parte de ellos en participar de los talleres de funk, pero, por otro, puede representar más un espacio de dominación y naturalización de lugares sociales que refuerzan las diferencias de género.

Palabras clave: Funk. Danza. Género. Juventud. 


\section{NOTAS}

1) Gangue: "1 associação de malfeitores; bando, quadrilha, grupo de pessoas; 2 ger. Jovens, às vezes com disposições agressivas; grupo, patota" (HOUAISS; VILLAR, 2009, p. 952).

2) Transcrevemos aqui trechos de algumas músicas:

"Só As Cachorras", do Bonde do Tigrão:

Só as cachorras

As preparadas

As popozudas

O baile todo

"Deixa a Cachorra Passar", Bonde do Tigrão

Não é tchutchuca e nem gatinha, é uma cachorra

Em todo o canto da cidade ela tá sempre por aí

É só olhar na cara dela ela só falta latir

É meia-noite é meio-dia ela nunca quer saber

Mexe o bumbum a toda a hora e me faz enlouquecer

"Agora Eu Sou Piranha", da Gaiola Das Popozudas

Eu vou pro baile procurar o meu negão

Vou subir no palco ao som do tamborzão

Sou cachorrona mesmo e late que eu vou passar

Agora eu sou piranha e ninguém vai me segurar!

"Loquinha", do McK9

Louca, louquinha

Tá louquinha, dá uma empinadinha

Safadinha

\section{REFERÊNCIAS}

ARAÚJO, T. História do funk: do soul ao batidão. Repórter Terra; funk carioca. Rio de Janeiro: 2005. Disponível em: <http://www.terra.com.br/reporterterra /funk/historia_do_funk.htm>. Acesso em: 9 jan. 2013.

ARRUDA, A.; JAMUR, M.; MELICIO, T.; BARROSO, F. De pivete a funqueiro: genealogia de uma alteridade. Cadernos de Pesquisa, São Paulo, v. 40, n. 140, p. 407-425, 2010.

BELEI, R.; GIMENIZ-PASCHOAL, S.; NASCIMENTO, E.; MATSUMOTO, P. O uso de entrevista, observação e videogravação em pesquisa qualitativa. Cadernos de Educação, Pelotas, n. 30, p. 187-199, jan./jun. 2008.

BOURDIEU, P. A dominação masculina. 3. ed. Rio de Janeiro: Bertrand Brasil, 2003. 
BRENNER, A.; DAYRELL, J.; CARRANO, P. Culturas do lazer e do tempo livre dos jovens brasileiros. In: ABRAMO, H.; BRANCO, P. Retratos da juventude brasileira. São Paulo: Perseu Abramo, 2005. p. 175-214.

CATANI, A. M.; GILIOLI, R. S. P. Diversidade de interpretações das culturas juvenis. In: Culturas juvenis: múltiplos olhares. São Paulo: UNESP, 2008. p. 89-103.

DAYRELL, J. O jovem como sujeito social. Revista Brasileira de Educação, Rio de Janeiro, n. 24, set./dez. 2003.

A música entra em cena: o rap e o funk na socialização da juventude em Belo Horizonte. Tese (Doutorado em Educação) - Programa de Pós-graduação da Faculdade de Educação da Universidade de São Paulo, São Paulo, SP, 2001.

HOUAISS, A.; VILLAR, M. Gangue. In: . Dicionário Houaiss da língua portuguesa. Rio de Janeiro: Objetiva, 2009. p. 952.

LIMA, A. Funkeiros, timbaleiros e pagodeiros: notas sobre juventude e música negra na cidade de Salvador. FUNK Brasil [blog]. Salvador, 2008.

Disponível em: <http://funk-brasil.blogspot.com.br>. Acesso em: 24 nov. 2012.

MELUCCI, A. Corpo-limite e corpo-mensagem. In: . O jogo do eu. São Leopoldo: UNISINOS, 2004. p. 91-104.

MINAYO, M. C. O desafio do conhecimento: pesquisa qualitativa em saúde. São Paulo: Hucitec, 2007.

MOISES. O funk e a libertação feminina. João Pessoa, 2011. Disponível em: <http:// temposinteressantes4.blogspot.com.br/2011/08/o-funk-e-libertacao-feminina. html>. Acesso em: 23 nov. 2012.

OLIVEIRA, E. A. C. A identidade feminina no gênero textual música funk. In: ENCONTRO DO CELSUL (8. : 2008 : PORTO Alegre,RS). [Anais] . Porto Alegre: CELSUL, 2008. Trabalho apresentado no GT Estudos em Análise Crítica do Discurso: questões de gênero social, de mídia e de educação. Disponível em: <http://www.celsul.org.br/ Encontros/08/identidade_feminina_funk.pdf>. Acesso em: 01 dez. 2012.

SCOTT, J. W. Gênero: uma categoria útil de análise histórica. Educação \& Realidade, Porto Alegre, v. 20, n. 2, p. 71-99, jul./dez. 1995.

SILVEIRA, D. T.; CÓRDOVA, F. P. A pesquisa Científica. In: GERHARDT, T. E.; SILVEIRA, D. T. Métodos de pesquisa. Porto Alegre: Editora da UFRGS, 2009.

SPOSITO, M. P. Juventude: crise, identidade e escola. In: DAYRELL, J. (Org). Múltiplos olhares sobre educação e cultura. Belo Horizonte: UFMG, 2006. p. 96-104.

WELLER, W. A presença feminina nas (sub)culturas juvenis: a arte de se tornar visível. Estudos Feministas, Florianópolis, v. 13, n. 1, p. 107-126, jan./abr. 2005. 
JaCIRA GIL BeRnARDES: Bibliotecária da Escola de Enfermagem da Universidade Federal do Rio Grande do Sul. Especialista pela UFRGS no Curso de Especialização em Administração de Sistemas de Bibliotecas. Mestre pelo Centro Universitário La Salle, no Mestrado Profissional em Memória Social e Bens Culturais.

E-mail: jacirasb@urrss.br

Paula Pinhal de Carlos: É professora do Centro Universitário La Salle - Canoas, atua como professora permanente do Mestrado em Direito e Sociedade e como professora colaboradora do Mestrado em Memória Social e Bens Culturais. É também professora do Centro Universitário Ritter dos Reis.

E-mail: paulapinhal@hotmail.com

Aline AcCORSSI: Doutora em Psicologia pela Pontifícia Universidade Católica do Rio Grande do Sul, com estágio na Escola de Altos Estudos em Ciências Sociais de Paris. Atualmente é professora no Curso de Pedagogia e professora-pesquisadora no PPG de Memória Social e Bens Culturais do Unilasalle. Coordena o grupo de pesquisa "Mariposas: Gênero, Sexualidades e Feminismos. Tem experiência na área de Psicologia, com ênfase em Psicologia Social e Comunitária, atuando principalmente nos seguintes temas: Teoria das Representações Sociais, Educação Popular, Identidades, Gênero e Pobreza.

E-mail: alineaccorssi@gmail.com 